\title{
Alterations of Serum IP-10 and TARC in Patients with Early Acute Rejection after Liver Transplantation
}

\author{
Xingchu Meng Wei Gao Ying Tang Zhenglu Wang Zhongyang Shen \\ Department of pediatric liver transplantation, Tianjin First Center Hospital, Tianjin, China
}

\section{Key Words}

Interferon- $\gamma$-Induced Protein 10 - Thymus and activation-regulated chemokine $\cdot$ Liver transplant rejection

\begin{abstract}
Background/Aims: To analyze alterations of interferon- $\nu$-induced protein 10 (IP-10) and thymus and activation-regulated chemokine (TARC) levels in early acute liver transplantation rejection. Methods: Thirty-six patients with early acute liver transplantation rejection were classified as non-, mild, moderate, and severe rejection groups. The levels of serum IP-10 and TARC were determined on days 3, 2, 1, and 0 before biopsy. Results: The IP-10 activities in all rejection groups were significantly higher $(p<0.05)$ than those in the non-rejection group at all time points and correlated with the extent of rejection $(p<0.05)$. The differences in TARC among the three rejection groups were significant $(p<0.05)$, and its highest level was found in the mild rejection group at all observed time points, whereas its lowest level was detected in the severe rejection group. The analysis of the TARC/IP-10 ratio revealed that the volume was correlated with the rejection degree. This ratio in the moderate and severe rejection groups on days 2,1 , and 0 before biopsy were $20 \%$ lower than that before transplantation. Conclusion: Serum IP-10 showed an increasing trend during early acute liver transplantation rejection. IP-10 increase or TARC/IP-10 ratio decrease combining with abnormal hepatic enzymatic alteration could be a valuable and specific sign for early rejection of the transplanted liver.
\end{abstract}

\section{Introduction}

The most severe liver disorder is liver failure which can result from viral hepatitis, cirrhosis, liver injury by alcohol or drugs, etc. The most efficient method to prevent the severe liver failure is liver transplantation. However, rejection of the transplanted liver tissue by the recipient's immune system will critically affect graft, especial patient survival 


\section{Cellular Physiology Cell Physiol Biochem 2017;41:1063-1071 \begin{tabular}{ll|l} 
DOI: 10.1159/000464114 2017 The Author(s). Published by S. Karger AG, Basel \\
and Biochemistry
\end{tabular} \\ Meng et al.: IP-10 and TARC levels in Early Acute Rejection}

state. The incidence of transplant rejection can be limited by determination of the molecular similitude between each specific donor and recipient, which facilitates the achievement of improved transplant compatibility. On the other hand, the administration of conventional immunosuppressive drug therapy to the recipient after the transplantation further decreases the risk of donor organ rejection by the recipient [1]. The employment of these measurements contributes to obtaining a balance between the tissues of the recipient and allograft, which is beneficial to the survival of allografts in the novel environment of the recipient. Breaking this balance results in the rejection of the allograft. According to its clinical properties and pathological/biochemical changes, liver transplant rejection can be divided into early acute, late acute, and chronic cellular [2]. The early acute cellular rejection occurs within one month after liver transplantation [3]. Early diagnosis is very important for prognosis and successful treatment to improve the patient and allograft survival rates [3-5].

Recently a growing body of biomedical research has been focused on the disease-related activities of chemokines. Interferon- $\gamma$ can induce monocytes, endothelial cells, and fibroblasts to secrete interferon- $\gamma$-induced protein 10 (IP-10), which is also known as C-X-C motif chemokine 10 (CXCL10) or small-inducible cytokine B10 [6]. IP-10 has several bioactivities, such as chemo attraction of monocytes/ macrophages, T cells, NK cells, and dendritic cells, promotion of T-cell adhesion to endothelial cells, antitumor activity, inhibition of bone marrow colony formation, and angiogenesis $[7,8]$. Scientists have noticed that some soluble cytokines and chemokines may participate in rescuing injured hepatocytes during the liver transplantation [9]. Besides being a marker of inflammatory damage, IP-10 expression was found to be related to the degree of liver inflammation, necrosis, and fibrosis $[10,11]$. It was perceived as well that IP-10 is involved in the heart and kidney allograft rejection $[12,13]$ and in the pluripotent stem cells and hepatocytes transplantation in mice acute liver failure models [9].

Thymus and activation-regulated chemokine (TARC), also known as chemokine (C-C motif) ligand 17 (CCL17), is a small cytokine of the CC chemokine family [14]. TARC is expressed mainly in the thymus, and only momentarily expressed in peripheral blood mononuclear cells under phytohemagglutinin-stimulation [14]. The activity of $\mathrm{T}$ cells is promoted by the interaction of the chemokine to its receptor, CCR4 [15]. TARC may be implicated in heart, skin, and lung allograft rejection in animal transplantation models [1618].

Early diagnosis of the rejection can provide more opportunities to rescue the patients and allografts. The most credible indicator for the diagnosis of the liver transplantation rejection is biopsy [4]. However, the opening wounds of biopsy frequently limit its clinical employment. Wang et al. deemed the increase in blood eosinophil counts as a valuable indicator for late acute rejection after liver transplantation [19]. No efficient predicator of early acute rejection after liver transplantation has been reported so far. Here, we propose that the level of IP-10 and TARC may correlate with the severity of the early acute rejection after liver transplantation.

In this study, we dynamically analyzed serum IP-10 and TARC levels in 36 patients diagnosed with different degrees of early acute rejection after liver transplantation. We found a correlation between the TARC/IP-10 ratio and the severity of the rejection. Thus, combining with abnormal alteration of hepatic enzymes it could be considered as a valuable and specific indicator for the clinical treatment and prognosis of early acute liver transplant rejection.

\section{Materials and Methods}

\section{Patients}

All the patients were hospitalized in the Department of Organ Transplantation, Tianjin First Central Hospital, Tianjin, China from January to August of 2004. During the 7-14 days after primary orthotopic liver transplantation, 36 patients (26 males and 10 females) who were suspected of having early acute 
Table 1. The general and clinical information of the patients. *: FK: Tacrolimus, $0.075 \mathrm{mg} / \mathrm{kg} / \mathrm{d}$; MMF: Mycophenolate mofetil, $750 \mathrm{mg} / \mathrm{kg} / \mathrm{d}$; MP: Methylprednisolone, day 0: $10 \mathrm{mg} / \mathrm{kg}$. iv; day 1:50 mg/kg. iv q6h; day 2: $25 \mathrm{mg} / \mathrm{kg}$. iv q6h; day 3: $20 \mathrm{mg} / \mathrm{kg}$. iv q12h; day 4: $10 \mathrm{mg} / \mathrm{kg}$. iv q12h; day 5-14: $8 \mathrm{mg} / \mathrm{kg}$. iv qd. ${ }^{ \pm}$: F: female. §: M: male

\begin{tabular}{|c|c|c|c|c|c|c|c|c|}
\hline \multirow{2}{*}{ No. } & \multirow{2}{*}{ Original disease } & \multicolumn{2}{|c|}{ Patient } & \multicolumn{2}{|c|}{ Donor } & \multirow{2}{*}{$\begin{array}{c}\text { Biospy time } \\
\text { (post operation days) }\end{array}$} & \multirow{2}{*}{ Imm. supper*. } & \multirow{2}{*}{ Banff. score } \\
\hline & & sex & age $(y)$ & sex & age (y) & & & \\
\hline 1 & Primary scleroding cholangitis & $\mathrm{F}^{E}$ & 17 & $\mathrm{M}^{\S}$ & 22 & 10 & $\mathrm{FK}+\mathrm{MMF}+\mathrm{MP}$ & 6 \\
\hline 2 & Primary liver cancer & M & 63 & M & 22 & 8 & $\mathrm{FK}+\mathrm{MMF}+\mathrm{MP}$ & $1-2$ \\
\hline 3 & Primary liver cancer & M & 46 & M & 21 & 13 & $\mathrm{FK}+\mathrm{MMF}+\mathrm{MP}$ & $4-5$ \\
\hline 4 & Hepatitis B cirrhosis & $\mathrm{F}$ & 55 & M & 26 & 8 & $\mathrm{FK}+\mathrm{MMF}+\mathrm{MP}$ & $6-7$ \\
\hline 5 & Primary biliary cirrhosis & $\mathrm{F}$ & 28 & M & 25 & 10 & $\mathrm{FK}+\mathrm{MMF}+\mathrm{MP}$ & 8 \\
\hline 6 & Hepatitis B cirrhosis & M & 37 & M & 21 & 13 & $\mathrm{FK}+\mathrm{MMF}+\mathrm{MP}$ & $4-5$ \\
\hline 7 & Hepatitis $\mathrm{C}$ cirrhosis & M & 39 & M & 22 & 10 & $\mathrm{FK}+\mathrm{MMF}+\mathrm{MP}$ & $4-5$ \\
\hline 8 & Hepatitis B cirrhosis & M & 44 & M & 22 & 10 & $\mathrm{FK}+\mathrm{MMF}+\mathrm{MP}$ & 8 \\
\hline 9 & Primary liver cancer & M & 59 & M & 35 & 12 & $\mathrm{FK}+\mathrm{MMF}+\mathrm{MP}$ & 3 \\
\hline 10 & Hepatitis B cirrhosis & M & 49 & M & 32 & 11 & $\mathrm{FK}+\mathrm{MMF}+\mathrm{MP}$ & $6-7$ \\
\hline 11 & Hepatitis B cirrhosis & M & 55 & M & 23 & 13 & $\mathrm{FK}+\mathrm{MMF}+\mathrm{MP}$ & 2 \\
\hline 12 & Hepatitis $\mathrm{C}$ cirrhosis & $\mathrm{F}$ & 55 & M & 22 & 13 & $\mathrm{FK}+\mathrm{MMF}+\mathrm{MP}$ & $\geq 8$ \\
\hline 13 & Primary liver cancer & M & 57 & M & 24 & 12 & $\mathrm{FK}+\mathrm{MMF}+\mathrm{MP}$ & 3 \\
\hline 14 & Primary liver cancer & M & 44 & M & 25 & 8 & $\mathrm{FK}+\mathrm{MMF}+\mathrm{MP}$ & 5 \\
\hline 15 & Primary liver cancer & M & 58 & M & 23 & 12 & $\mathrm{FK}+\mathrm{MMF}+\mathrm{MP}$ & $\geq 8$ \\
\hline 16 & Hepatitis C cirrhosis & M & 48 & M & 27 & 13 & $\mathrm{FK}+\mathrm{MMF}+\mathrm{MP}$ & $4-5$ \\
\hline 17 & Primary biliary cirrhosis & $\mathrm{F}$ & 46 & M & 30 & 12 & $\mathrm{FK}+\mathrm{MMF}+\mathrm{MP}$ & 7 \\
\hline 18 & Hepatitis B cirrhosis & M & 49 & M & 28 & 8 & $\mathrm{FK}+\mathrm{MMF}+\mathrm{MP}$ & 5 \\
\hline 19 & Hepatitis $C$ cirrhosis & M & 52 & M & 24 & 11 & $\mathrm{FK}+\mathrm{MMF}+\mathrm{MP}$ & $1-2$ \\
\hline 20 & Primary liver cancer & M & 55 & M & 25 & 9 & $\mathrm{FK}+\mathrm{MMF}+\mathrm{MP}$ & $6-7$ \\
\hline
\end{tabular}

Table 2. Analysis of the liver functional blood test. ALT: alanine aminotransferase; AST: aspartate aminotransferase; TBIL: total bilirubin. $\uparrow: p<0.05$, compared to the control; $¥: p<0.05$, compared to the non-rejection; $€: p<0.05$, compared to the mild-rejection; All data are shown as mean \pm SD

\begin{tabular}{llllll}
\hline & Control $(\mathrm{n}=8)$ & Non-rejection $(\mathrm{n}=8)$ & Mild rejection $(\mathrm{n}=15)$ & Moderate rejection $(\mathrm{n}=8)$ & Severe rejection $(\mathrm{n}=5)$ \\
\hline ALT & $18.4 \pm 8.8$ & $356.2 \pm 108.4 \dagger$ & $264.3 \pm 69 \dagger$ & $493.1 \pm 53 \dagger, €$ & $749,2 \pm 122,1 \dagger, ¥, €$ \\
AST & $19.4 \pm 5.5$ & $341.4 \pm 78.8 \dagger$ & $341.1 \pm 89.4 \dagger$ & $606 \pm 211.9 \dagger$ & $863.2 \pm 170.7 \dagger, ¥, €$ \\
TBIL & $17.3 \pm 6.4$ & $76 \pm 44.4 \dagger$ & $81.8 \pm 33.2 \dagger$ & $94.5 \pm 44.2 \dagger$ & $100.5 \pm 10.2 \dagger$ \\
\hline
\end{tabular}

rejection were selected for the study. They were between 17 and 63 years old, with an average age of 49 years. The patients were undergone immunosuppressive therapy with $0.075 \mathrm{mg} / \mathrm{kg} / \mathrm{d}$ Tacrolimus (FK506), $750 \mathrm{mg} / \mathrm{kg} / \mathrm{d}$ Mycophenolate mofetil (MMF), and Methylprednisolone (day 0: $10 \mathrm{mg} / \mathrm{kg}$. iv; day 1: $50 \mathrm{mg}$ / kg. iv q6h; day 2: $25 \mathrm{mg} / \mathrm{kg}$. iv q6h; day 3: $20 \mathrm{mg} / \mathrm{kg}$. iv q12h; day 4: $10 \mathrm{mg} / \mathrm{kg}$. iv q12h; day 5-14: $8 \mathrm{mg} / \mathrm{kg}$. iv qd.). The inductive therapy was performed with Basiliximab (day 0: $20 \mathrm{mg}$. iv; day 4:20mg. iv). Once the patients were suspected to suffer from early acute cellular rejection after liver transplantation, a liver biopsy was performed for pathological diagnosis. The detail general and clinical information and liver functional blood tests of these patients were listed in Table 1 and 2. This study was conducted with the approval of the Institutional Human Ethics Committee of Tianjin First Central Hospital.

\section{Group classification}

Depending on the pathological characteristics (the data are not shown here) of the liver biopsy and Banff Schema [20], the patients were divided into specific groups: non-rejection (Banff score $\leq 3$ ), with 8 patients; mild rejection (Banff score 4-5), with 15 patients; moderate rejection (Banff score 6-7), with 8 patients; and severe rejection (Banff score s 8), with 5 patients. 


\section{Cellular Physiology $\quad$ Cell Physiol Biochem 2017;41:1063-1071 \begin{tabular}{ll|l} 
Ond 2017 The Author(s). Published by S. Karger AG, Basel \\
and Biochemistry
\end{tabular} \\ Meng et al.: IP-10 and TARC levels in Early Acute Rejection}

Serum collection and biopsy

All the patients who received a liver transplant operation were underwent a conventional daily examination in the first two-weeks to monitor the hepatic enzymes level. Once the patient's serum alanine aminotransferase (ALT), aspartate aminotransferase (AST), and total bilirubin (TBIL) levels did not show a declining trend as normal but increased, meantime, other reasons (such as severe infection or surgical reasons) were excluded, he-she was considered to do a biopsy. Therefore, all the previous examined data (include $-3,-2$, and -1 day) were available for every patient.

Peripheral venous blood was collected from the fasting patients on days 3, 2, 1, and 0 before liver biopsy. The serum samples collected before liver transplantation were used as a negative control. The blood was kept for $30 \mathrm{~min}$ at room temperature and centrifuged at $6200 \mathrm{xg}$ for $10 \mathrm{~min}$ at $4^{\circ} \mathrm{C}$. Then, the supernatant serum was withdrawn, transferred into an Eppendorf tube, and stored at $-20^{\circ} \mathrm{C}$.

Assays of IP-10 and TARC activity by enzyme-linked immunosorbent assay (ELISA)

The serum activities of IP-10 and TARC were assayed by using human CXCL10/IP-10 (BGI, Cambridge, MA, USA) and CCL17/TARC (BGI, USA) ELISA kits. The assays were performed following the standard protocol provided by the kit instructions. IP-10 and TARC concentrations were calculated as ng/L as directed by the instructions.

\section{Statistical analysis}

Comparative analyses among groups were performed using the Kruskal-Wallis method. Once the difference was found to be statistically significant, a multiple pairwise comparisons analysis was carried out by the Nemenyi SNK method. Before and after the treatment, a comparative analysis within each group was conducted by the $t$-test or the Wilcoxon signed-rank test. The differences were considered statistically significant at $p<0.05$.

\section{Results}

Serum IP-10 levels in the different groups

The serum IP-10 level was determined in all groups on days 3, 2, 1, and 0 before the liver biopsy. In all the rejection groups, the IP-10 levels were higher than those in the nonrejection group, in which a similar IP-10 level was maintained in all four days (Fig. 1). In all the rejection groups, this level was significantly higher at each time point $(p<0.05)$ than that in the non-rejection group. The changing pattern of the IP-10 level in the liver transplant rejection exhibited a positive correlation between the rejection grade and the IP-10 level. These alterations were significant before and after the liver biopsy $(p<0.05)$ (Fig. 1).

\section{Serum TARC levels in the different groups}

Among all groups at all-time points, the highest TARC concentration was found in the mild rejection group, and the lowest was detected in the severe rejection group (Fig. 2). The difference in the TARC activity between the mild/severe and the non-rejection group was significantly higher $(p<0.05)$. On the other hand, the level of TARC in the moderate rejection group did not differ from that in the non-rejection group $(p>0.05)$. A remarkable trend of reduction was observed in the severe rejection group along with approaching the day of the diagnosis (day 0). Yet, the other groups did not show any trend.

\section{TARC/IP-10 ratio in all groups}

To effectively evaluate the tolerance of the recipients to the graft, we investigated the trends in the ratio TARC/IP-10 in all studied groups (Fig. 3). Before liver transplantation, the values of the TARC/IP-10 ratios were similar in all the patients. After the liver transplantation, the TARC/IP-10 ratio in the non-rejection group sustained at a relatively high level (within the range 1.39-1.59 ng/L). Compared to the non-rejection group, in the mild rejection group these ratios were not different on days 3 and 2 before the liver biopsy $(p>0.05)$, but decreased considerably $(p<0.05)$ on days 1 and 0 prior to liver biopsy. As expected, the 


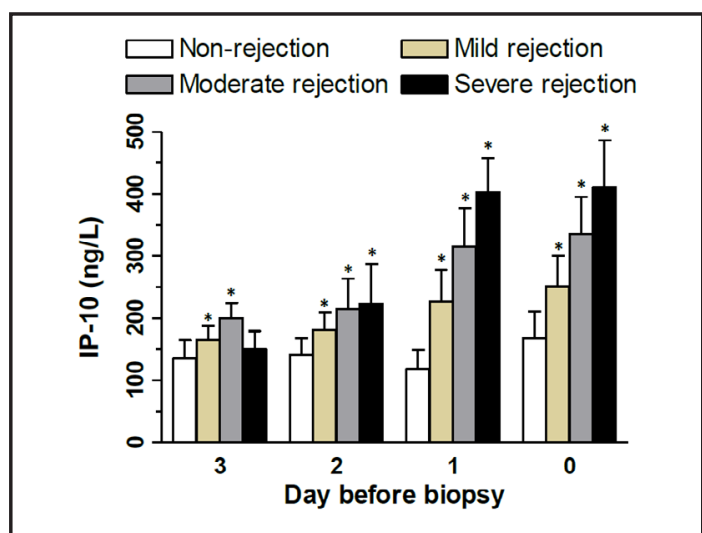

Fig. 1. Serum IP-10 concentrations in the different groups on the indicated day before biopsy. The serum was collected from the patients in the non-rejection (open bar; $n=5$ ), mild rejection (light gray bar; $\mathrm{n}=15$ ), moderate rejection (dark gray bar; $\mathrm{n}=$ 8), and severe rejection (solid bar; $n=8$ ) groups on the indicated days. The serum IP-10 concentrations were detected by ELISA and represented as average values. Statistical analysis: * indicated the statistic difference $(p<0.05)$ compared to non-rejection group. All data are shown as mean \pm SD.

Fig. 3. Serum TARC/IP-10 ratio at the indicated time compared to that before the transplantation. The ratio was calculated based on the data of Fig. 1 and 2 at the indicated time. Statistical analysis: a refers to $P<0.05$ compared to the non-rejection group; $\mathrm{b}$ indicates $P<0.05$ compared to the mild rejection group; c represents $P<0.05$ compared to the moderate rejection group. Compared to the ratio before transplantation, on days 3-0 in the non-rejection group, on days 1-0 in the moderate rejection group, and on days 2-0 in the severe rejection group before biopsy are significant $(P<0.05)$. All data are shown as mean $\pm \mathrm{SD}$.

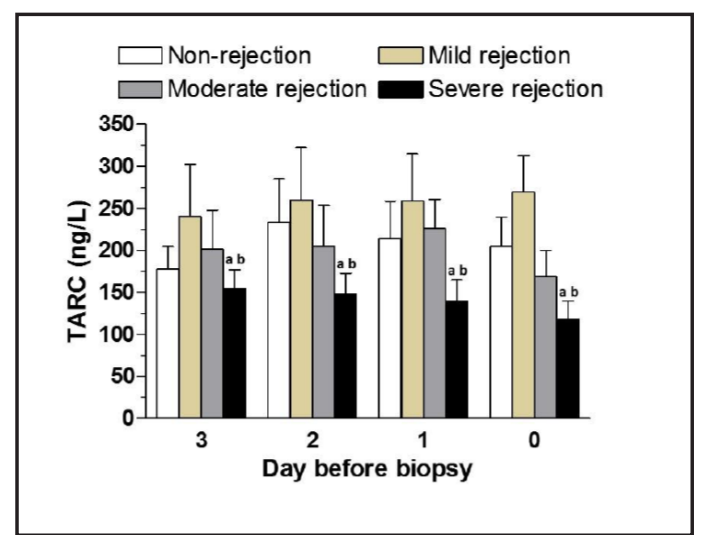

Fig. 2. Serum TARC concentrations in the different groups on the indicated day before biopsy. The serum TARC concentrations were detected by ELISA and represented as average values. The method of serum collection was identical to that described in Fig.1. Statistical analysis: a indicated the statistic difference $(p<0.05)$ compared to non-rejection group. b indicated the statistic difference $(p<0.05)$ compared to mild-rejection group. All data are shown as mean \pm SD.

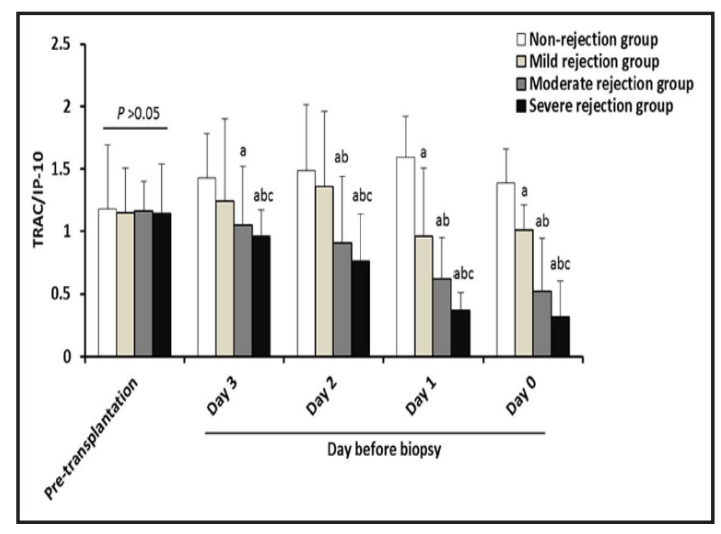

TARC/IP-10 ratio in the moderate and the severe rejection groups dropped significantly $(p<$ $0.05)$. The comparative evaluation of all the groups revealed a tendency of the occurrence of a more serious rejection when the values of the TARC/IP-10 ratio were decreased.

\section{Discussion}

A study by Kunzendorf et al. suggested that $\mathrm{T}_{\mathrm{H}} 1$ cells exert a major role in the immune response in acute cellular rejection after liver transplantation [21]. The $\mathrm{T}_{\mathrm{H}} 1$ cells activated by a donor-specific antigen were enhanced by chemokines and their receptors to migrate from the periphery to the transplanted organ [22]. The neutralization of a single chemokine with a monoclonal antibody can prolong the allograft survival in heart- and kidney-transplanted animal models. The most pronounced effects were obtained by prohibiting the IP-10 receptor CXCR3 [23] or the CC-chemokine receptor 5 (CCR5) [24]. In this study, the IP-10 
level in the non-rejection control group was relatively low. In the other rejection groups, the IP-10 level showed a trend for an increase of varying degrees during the episodes of acute rejection, and was significantly higher than that of the non-rejection control $(p<0.05)$. There was a positive correlation between the concentration of IP-10 and the degree of rejection (Fig. 1). Our results suggested that the increased IP-10 level in all allograft rejection groups indicated that $\mathrm{T}_{\mathrm{H}} 1$ cells participated in the inflammation process. Furthermore, IP-10 as a chemokine secreted by $\mathrm{T}_{\mathrm{H}} 1$ cells $[25,26]$ is deeply involved in early acute allograft transplant rejection [27]. Indeed, IP-10 plays an important role to maintain a balance between allograft and recipient. In a rat intestinal transplantation study, $\mathrm{Xu}$ et al. found that the group of bone merrow transfusion containing with dendric cell silence obtained good health, less pathological injury, and less rejection, which is correlated with serum IL-2 decreases and serum IL-10 increases [28]. As well, in a heart transplantation study, Gassa et al showed that Knock-out IP-10 could result in a over immune response, liver dysfunction, and even death [29]. Since the acute rejection after liver transplantation is an exceedingly complex process, factors involved other than IP-10 are awaiting to be explored.

TARC is a $\mathrm{T}_{\mathrm{H}} 2$ cell chemokine, whose receptor, CCR4, is distributed mostly on the surface of $\mathrm{T}_{\mathrm{H}} 2$ cells [30]. The reaction between the chemokines and their receptors contributes to the allograft rejection progress [31]. Actually, TARC is reported to be involved in allograft rejection in some animal models $[16,17]$. However, it is still uncertain whether $\mathrm{T}_{\mathrm{H}} 2$ cells and their cofactors participate in human allograft rejection process. In our investigation, the level of TARC was the highest in the mild rejection group among all observed groups. Conversely, the level of TARC in the severe rejection group was the lowest. Indeed, the trend of a decline is clear and noticeable. The explanation could be that TARC may attract $\mathrm{T}_{\mathrm{H}} 2$ cells to participate in the rejection process in the early stage of the allograft rejection $[16,17]$. However, in the later period of the acute allograft rejection progress, the increased IP-10 levels combined with the decreased TARC expression revealed that the $\mathrm{T}_{\mathrm{H}} 1$ chemokines obtain an advantage due to the antagonistic relationship between the chemokines secreted by $\mathrm{T}_{\mathrm{H}} 1$ and $\mathrm{T}_{\mathrm{H}} 2$ cells. This inference is consistent with the results in a previous report that IP-10 gradually became the protagonist during the acute allograft rejection progress [32].

In a renal allograft acute rejection study, Oliveira et al. indicated that $\mathrm{T}_{\mathrm{H}} 1$ cells are involved in acute allograft rejection process. $\mathrm{T}_{\mathrm{H}} 2$ cells, on the other hand, contribute to the chronic kidney rejection [33]. The balance between $\mathrm{T}_{\mathrm{H}} 1$ and $\mathrm{T}_{\mathrm{H}} 2$ cells is crucial for inducing or avoiding the allograft rejection. Sayegh et al. [34] found that the mRNA expression of the cytokines for $\mathrm{T}_{\mathrm{H}} 1 \mathrm{in}$ an animal model of heart transplantation were upregulated after allograft rejection. However, after the transplantation, the number of $\mathrm{T}_{\mathrm{H}} 2$ cells in the spleen of the nonrejection mice was much higher than that of $\mathrm{T}_{\mathrm{H}} 1$. Infiltration of scattered lymphocytes was observed in the antibody-induced immune suppression after heart transplantation in mice. Here also, the number of $\mathrm{T}_{\mathrm{H}} 1$ cells declined considerably, whereas that of $\mathrm{T}_{\mathrm{H}} 2$ was augmented. These data suggested that the balance between $\mathrm{T}_{\mathrm{H}} 1$ and $\mathrm{T}_{\mathrm{H}} 2$ cells do play an important role during the allograft rejection progress. Suppression of the $\mathrm{T}_{H} 1$ cell activity would stimulate the $\mathrm{T}_{\mathrm{H}} 2$ activity. In our study, IP-10 represented the typical $\mathrm{T}_{\mathrm{H}} 1$ cell cytokine, and the TRAC was used as a representative of $\mathrm{T}_{\mathrm{H}} 2$ cell cytokines. To assess the dynamics of the balance between $\mathrm{T}_{\mathrm{H}} 1$ and $\mathrm{T}_{\mathrm{H}} 2$ cells, we set up the TRAC/IP-10 ratio as an indicator. The situation of the immune suppression and allograft rejection after transplantation was revealed. From our results, we discovered that the degree of the severity of the early acute allograft rejection is consistent with the decline in the ratio TRAC/IP-10 (Fig. 3). This finding indicates that the immune suppression status is broken, and allograft rejection process is underway in these patients. The dynamic observation of the ratio in the moderate and severe rejection groups indicated the effectiveness of the current treatment or prompted us to change to another measurement. Meanwhile, the ratios were relatively higher in the non-rejection and the mild rejection groups, which suggested that immune tolerance was induced by chemokines of $\mathrm{T}_{\mathrm{H}} 2$. Continued supervision of this ratio in the non- and mild rejection groups helped us to predict the tendency to turn to accept or reject the allograft by the recipient's immune system. To facilitate and clarify our judgements, we illustrated the ratio of the TRAC/IP-10 expressed as 


\section{Cellular Physiology Cell Physiol Biochem 2017;41:1063-1071

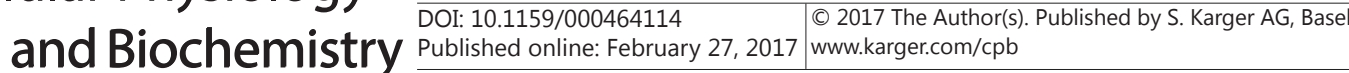 \\ Meng et al.: IP-10 and TARC levels in Early Acute Rejection}

Fig. 4. Serum TARC/IP-10 ratio in the different groups at the indicated time. The ratio of TARC/ IP-10 was calculated based on the data presented in Fig. 3. The percentage was calculated by comparing the ratio of the indicated day to that before the transplantation. The horizontal dotted line represents the value of $20 \%$.

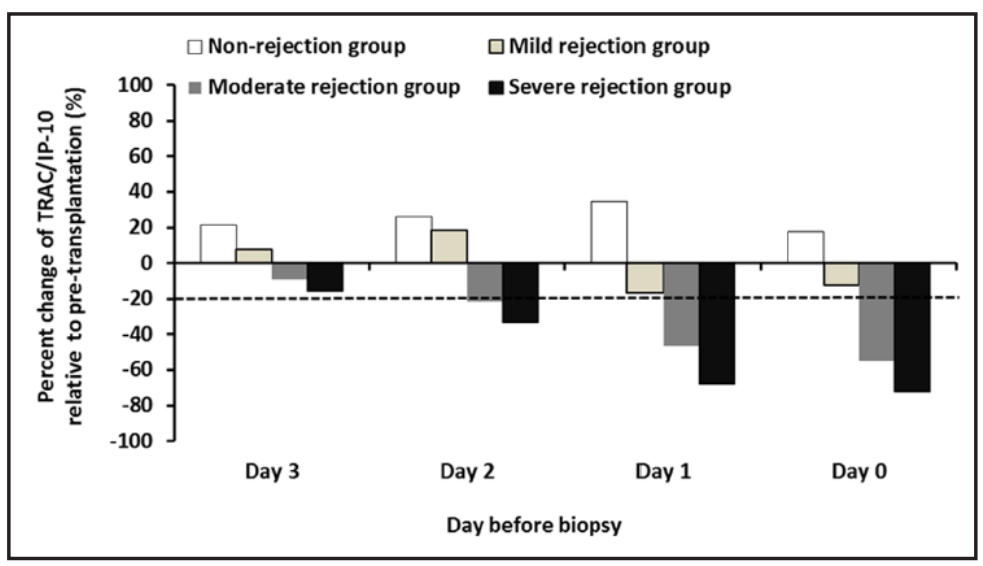

a percentage (Fig. 4). We found that the post-transplantation decline of $20 \%$ in the ratio was turning point to estimate the severity of early acute allograft rejection. In contrast, values the ratio above $20 \%$ revealed that the allograft was completely accepted by the recipient (see the non-rejection group in Fig. 4). The ratio between $+20 \%$ and $-20 \%$ meant the status may be considered as "mild rejection". However, the decrease of the ratio RTAC/IP-10 below 20\% indicated that a serious rejection had happened. A strength measurement is necessary for the patients, and the further changes of the ratio will indicate the effect of the measurement.

Comparing to the liver function test, on the whole tendency, the damage degree of the liver parenchymal (increase of ALT, AST, and BILT, in Table 1) is positive correlation with the elevation of serum CXCL10, although the ALT level in non-rejection group is higher than that in mild-refection group. Furthermore, the tendency of the damage of liver function is negatively correlation with the TRAC/IP-10 ratio.

\section{Conclusion}

The IP-10 expression is increased after early acute allograft rejection progress, and the severity of the rejection is parallel with the level of IP-10. Meanwhile, the TRAC expression is reduced during acute allograft rejection process. Conversely, the level of allograft rejection is inversely related to the level of TRAC. The ratio TRAC/IP-10 could be a valuable predicator for the acceptance or rejection of allografts transplants by the recipient. A TRAC/IP-10 ratio that is lower than $20 \%$ is a crucial indicator that early acute rejection is occurring. The practical value of TRAC/IP-10 needs to be clinically validated in investigations including more patients with liver allograft rejection and other types of allograft rejection.

\section{Disclosure Statement}

All the authors declare that they have no conflict of interest.

\section{References}

1 Frohn C, Fricke L, Puchta JC, Kirchner H: The effect of hla-c matching on acute renal transplant rejection. Nephrol Dial Transplant 2001;16:355-360.

-2 Neil DA, Hübscher SG: Current views on rejection pathology in liver transplantation. Transpl Int 2010;23:971-983.

- Nacif LS, Pinheiro RS, Pécora RAdA, Ducatti L, Rocha-Santos V, Andraus W, D’Albuquerque LC: Late acute rejection in liver transplant: A systematic review. ABCD Arquivos Brasileiros de Cirurgia Digestiva (São Paulo) 2015;28:212-215. 


\section{Cellular Physiology Cell Physiol Biochem 2017;41:1063-1071

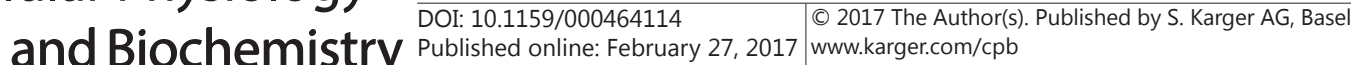 \\ Meng et al.: IP-10 and TARC levels in Early Acute Rejection}

4 Neil D, Hubscher S: Delay in diagnosis: A factor in the poor outcome of late acute rejection of liver allografts: Transplant Proc 2001; 33: 1525-1526.

5 Thurairajah PH, Carbone M, Bridgestock H, Thomas P, Hebbar S, Gunson BK, Shah T, Neuberger J: Late acute liver allograft rejection; a study of its natural history and graft survival in the current era. Transplantation 2013; 95: 955-959.

6 Luster AD, Unkeless JC, Ravetch JV: $\Gamma$-interferon transcriptionally regulates an early-response gene containing homology to platelet proteins. Nature 1985; 315: 672-676.

7 Dufour JH, Dziejman M, Liu MT, Leung JH, Lane TE, Luster AD: Ifn- $\gamma$-inducible protein 10 (ip-10; cxcl10)deficient mice reveal a role for ip-10 in effector t cell generation and trafficking. J Immunol 2002;168:31953204.

8 Angiolillo AL, Sgadari C, Taub DD, Liao F, Farber JM, Maheshwari S, Kleinman HK, Reaman GH, Tosato G: Human interferon-inducible protein 10 is a potent inhibitor of angiogenesis in vivo. J Exp Med 1995;182:155-162.

$>9$ Chan C-C, Cheng L-Y, Lu J, Huang Y-H, Chiou S-H, Tsai P-H, Huo T-I, Lin H-C, Lee F-Y: The role of interferon- $\gamma$ inducible protein-10 in a mouse model of acute liver injury post induced pluripotent stem cells transplantation. PloS One 2012;7:e50577.

10 Zeremski M, Petrovic LM, Chiriboga L, Brown QB, Yee HT, Kinkhabwala M, Jacobson IM, Dimova $\mathrm{R}$, Markatou M, Talal AH: Intrahepatic levels of cxcr3-associated chemokines correlate with liver inflammation and fibrosis in chronic hepatitis c. Hepatology 2008;48:1440-1450.

11 Bone-Larson CL, Hogaboam CM, Evanhoff H, Strieter RM, Kunkel SL: Ifn- $\gamma$-inducible protein-10 (cxcl10) is hepatoprotective during acute liver injury through the induction of cxcr2 on hepatocytes. J Immunol 2001;167:7077-7083.

12 Zhao DX, Hu Y, Miller GG, Luster AD, Mitchell RN, Libby P: Differential expression of the ifn-gammainducible cxcr3-binding chemokines, ifn-inducible protein 10, monokine induced by ifn, and ifn-inducible $t$ cell alpha chemoattractant in human cardiac allografts: Association with cardiac allograft vasculopathy and acute rejection. J Immunol 2002;169:1556-1560.

13 Fairchild RL, Suthanthiran M: Urine cxcl10/ip-10 fingers ongoing antibody-mediated kidney graft rejection. J Am Soc Nephrol 2015;26:2607-2609.

14 Imai T, Yoshida T, Baba M, Nishimura M, Kakizaki M, Yoshie O: Molecular cloning of a novel t cell-directed cc chemokine expressed in thymus by signal sequence trap using epstein-barr virus vector. J Biol Chem 1996;271:21514-21521.

15 Imai T, Baba M, Nishimura M, Kakizaki M, Takagi S, Yoshie O: The t cell-directed cc chemokine tarc is a highly specific biological ligand for cc chemokine receptor 4. J Biol Chem 1997;272:15036-15042.

-16 Hüser N, Tertilt C, Gerauer K, Maier S, Traeger T, Aßfalg V, Reiter R, Heidecke CD, Pfeffer K: Ccr4-deficient mice show prolonged graft survival in a chronic cardiac transplant rejection model. Eur J Immunol 2005;35:128-138.

17 Li B, Xu W, Xu L, Jiang Z, Wen Z, Li K, Xiong S: I-tac is a dominant chemokine in controlling skin intragraft inflammation via recruiting cxcr3+ cells into the graft. Cell Immunol 2010;260:83-91.

-18 Paantjens AW, van de Graaf EA, Kwakkel-van Erp JM, Hoefnagel T, van Kessel DA, van den Bosch JM, Otten HG: Lung transplantation affects expression of the chemokine receptor type 4 on specific t cell subsets. Clin Exp Immunol 2011;166:103-109.

19 Wang GY, Li H, Liu W, Zhang J, Zhu H-B, Wang G-S, Zhang Q, Yang Y, Chen G-H: Elevated blood eosinophil count is a valuable biomarker for predicting late acute cellular rejection after liver transplantation: Transplant Proc 2013; 45: 1198-1200.

20 Demetris AJ, Batts KP, Dhillon AP, Ferrell L, Fung J, Geller SA, Hart J, Hayry P, Hofmann WJ, Hubscher S: Banff schema for grading liver allograft rejection. Hepatology 1997;25:658-663.

21 Kunzendorf U, Tran TH, Bulfone-Paus S: The th1-th2 paradigm in 1998: Law of nature or rule with exceptions. Nephrol Dial Transplant 1998;13:2445-2448.

22 Baggiolini M: Chemokines and leukocyte traffic. Nature 1998;392:565-568.

23 Jiankuo M, Xingbing W, Baojun H, Xiongwin W, Zhuoya L, Ping X, Yong X, Anting L, Chunsong H, Feili G, Jinquan T: Peptide nucleic acid antisense prolongs skin allograft survival by means of blockade of cxcr3 expression directing t cells into graft. J Immunol 2003;170:1556-1565. 


\section{Cellular Physiology Cell Physiol Biochem 2017;41:1063-1071 \begin{tabular}{ll|l} 
and Biochemistry & $\begin{array}{l}\text { DOI: 10.1159/000464114 } \\
\text { Published onlne: February 27, } 2017\end{array}$ & $\begin{array}{l}\text { O 2017 The Author(s). Published by S. Karger AG, Basel } \\
\text { www.karger.com/cpb }\end{array}$ \\
\cline { 2 - 3 }
\end{tabular}}

Meng et al.: IP-10 and TARC levels in Early Acute Rejection

24 Jun L, Kailun Z, Aini X, Lei X, Guohua W, Sihua W, Ping Y, Tucheng S, Xionggang J, Wenwei C: Retracted: Combined treatment with chemokine receptor 5 blocker and cyclosporine induces prolonged graft survival in a mouse model of cardiac transplantation. J Heart Lung Transplant 2010;29:461-470.

25 Flier J, Boorsma DM, van Beek PJ, Nieboer C, Stoof TJ, Willemze R, Tensen CP: Differential expression of cxcr3 targeting chemokines cxcl10, cxcl9, and cxcl11 in different types of skin inflammation. J Pathol 2001;194:398-405.

-26 Gottlieb AB, Luster AD, Posnett DN, Carter D: Detection of a gamma interferon-induced protein ip-10 in psoriatic plaques. J Exp Med 1988;168:941-948.

27 Tatapudi RR, Muthukumar T, Dadhania D, Ding R, Li B, Sharma VK, Lozada-Pastorio E, Seetharamu N, Hartono C, Serur D: Noninvasive detection of renal allograft inflammation by measurements of mrna for ip-10 and cxcr3 in urine. Kidney Int 2004;65:2390-2397.

28 Xu X, Gao X, Zhao X, Liao Y, Ji W, Li Q Li J: Pu. 1-silenced dendritic cells induce mixed chimerism and alleviate intestinal transplant rejection in rats via a th1 to th2 shift. Cell Physiol Biochem 2016;38:220-228.

29 Gassa A, Jian F, Kalkavan H, Duhan V, Honke N, Shaabani N, Friedrich S-K, Dolff S, Wahlers T, Kribben A: Il-10 induces t cell exhaustion during transplantation of virus infected hearts. Cell Physiol Biochem 2016;38:1171-1181.

-30 Imai T, Nagira M, Takagi S, Kakizaki M, Nishimura M, Wang J, Gray PW, Matsushima K, Yoshie O: Selective recruitment of ccr4-bearing th2 cells toward antigen-presenting cells by the cc chemokines thymus and activation-regulated chemokine and macrophage-derived chemokine. Int Immunol 1999;11:81-88.

31 Hancock WW, Gao W, Faia KL, Csizmadia V: Chemokines and their receptors in allograft rejection. Curr Opin Immunol 2000;12:511-516.

-32 Zambernardi A, Chiodetti A, Meier D, Cabanne A, Nachman F, Solar H, Rumbo C, Gondolesi GE, Rumbo M: Immunosuppressive therapies after intestinal transplant modulate the expression of th1 signature genes during acute cellular rejection. Implications in the search for rejection biomarkers. Clin Transplant 2014;28:1365-1371.

33 Oliveira G, Xavier P, Murphy B, Neto S, Mendes A, Sayegh MH, Guerra LE: Cytokine analysis of human renal allograft aspiration biopsy cultures supernatants predicts acute rejection. Nephrol Dial Transplant 1998;13:417-422.

34 Sayegh MH, Akalin E, Hancock WW, Russell ME, Carpenter CB, Linsley PS, Turka LA: Cd28-b7 blockade after alloantigenic challenge in vivo inhibits th1 cytokines but spares th2. J Exp Med 1995;181:1869-1874. 